\title{
OS MURAIS DE PORTINARI EM WASHINGTON
}

\author{
Marcelo Mari
}

Professor da Faculdade de Tecnologia de São Paulo

\section{A missão cultural norte-americana e Cândido Portinari}

Até pelo menos 1943, quando o destino da Alemanha nazista pareceu estar consumado, as relações políticas e econômicas dos Estados Unidos com a América Latina foram consideradas prioritárias e, de fato, possibilitaram o desenvolvimento e a ampliação hegemônica da cultura, da indústria e da economia norte-americanas no mundo do Pós-Guerra. Por isso, o intercâmbio e a política cultural dos Estados Unidos para o continente americano estiveram ligados de forma invariável às estratégias políticas internacionais e às atividades propagandistas. Tacuchian diz: "O centro das decisões permaneceu no Departamento de Estado, pois as ações panamericanas envolviam relações diplomáticas internacionais. $\mathrm{O}$ Departamento controlava e exercia poder de veto sobre as propostas lançadas por outras agências (entre elas, a União Panamericana). Outro braço do programa era o OCIAA (...), agência emergencial formada para responder aos desafios gerados pela situação de guerra, e apesar de voltado primordialmente para a formulação de um programa econômico estratégico para o Hemisfério, tinha nas atividades culturais uma base de sustentação para a reformulação das mentalidades. Neste contexto, em que a política cultural e a propaganda mesclavam-se, o programa (artístico) (...) foi formulado com a finalidade de envolver a comunidade intelectual norteamericana na sua totalidade, abrangendo diferentes associações representativas de setores diversos, tais como o de educadores, musicólogos, artistas, orquestras, universidades, associações cívicocomunitárias e mesmo esferas governamentais ligadas à cultura, como a Biblioteca do Congresso."1

As atividades culturais eram eficazes na persuasão e na construção de uma imagem positiva dos Estados Unidos e de sua política no Brasil.

\footnotetext{
1 TACUCHIAN, M. de F. G. Panamericanismo, propaganda e música erudita: Estados Unidos e o Brasil (1939-1948). Tese de doutorado apresentada ao Departamento de História da Faculdade de Filosofia, Letras e Ciências Humanas da Universidade de São Paulo. Orientador: Prof. Dr. Arnaldo Daraya Contier. 1998, pp. 48-49. (parênteses nossos)
} 
Por diversos meios, a Política da Boa Vizinhança se efetivava: a publicação de artigos e de reportagens completas em jornais e revistas norteamericanos sobre o Brasil e várias de suas personalidades; a difusão de programas da NBS, da CBS e de outras companhias radiofônicas, falados em português e voltados para o público brasileiro; a organização de expedições culturais de escritores, cineastas e artistas norte-americanos para conhecer o Brasil e sua cultura; a concessão de verbas para a ida dos artistas brasileiros consagrados para os Estados Unidos. A instituição que teve mais influência na execução dessas tarefas foi, sem dúvida, a OCIAA. Antônio Pedro Tota comenta: "A agência criada por Roosevelt e dirigida pelo magnata Nelson Rockfeller tinha (...) duas importantes incumbências: difundir entre os americanos uma imagem positiva dos países latinoamericanos, em especial do Brasil, e convencer os brasileiros de que os Estados Unidos sempre foram amigos do Brasil. Essas foram as tarefas levadas a cabo pelos meios de comunicação de massa, que se consolidavam nos anos 40." 2

O grande evento que marcou o início da aproximação cultural entre o Brasil e os Estados Unidos foi a Feira Mundial de Nova York em 30 de abril de 1939. Nela, o governo brasileiro montou um pavilhão com tudo o que caracterizava o país naquele momento e lá foram expostos desde produtos de interesse para venda até símbolos de modernidade e obras da cultura brasileira. Tota diz: "A New York World's Fair abriu suas portas (...). Uma imensa vitrine de sofisticadas bugigangas foi apresentada para visitantes do mundo todo. Os brasileiros que (...) visitaram a Feira, ou que consultaram jornais e revistas, mal puderam conter a admiração. Ficaram atônitos diante de aparelhos de barbear, máquinas de lavar roupas, primitivos aparelhos de televisão e robôs. (...) O Brasil, assim como vários outros países, participou da (...) (Feira). O pavilhão brasileiro foi projetado por Lúcio Costa e Oscar Niemeyer. E, no lançamento da pedra fundamental do edifício, ouviu-se o discurso do ministro da Indústria, Comércio e Trabalho, dr. Waldemar Falcão, transmitido em ondas curtas do Brasil para os Estados Unidos. (...) Uma banda tocou o Hino Nacional. Logo a seguir, o discurso do ministro brasileiro enaltecia a Política da Boa

2 TOTA, A. P. O imperialismo sedutor: a americanização do Brasil na época da Segunda Guerra. São Paulo: Companhia das Letras, 2000, p. 54. 
Vizinhança, '[...] tão preconizada pelos presidentes Roosevelt e Getúlio Vargas [...]"”. ${ }^{3}$

Nas artes plásticas, Cândido Portinari foi escolhido para representar o Brasil nos Estados Unidos e preparou três obras para a Feira: "Jangadas do Nordeste", "Cena Gaúcha" e "Festa de São João". Embora o Pintor tivesse recebido apoio entusiástico de intelectuais ligados ao Ministério da Educação, tais como Carlos Drummond de Andrade e Mário de Andrade, o círculo mais próximo do ministro Gustavo Capanema e também grande parte do meio artístico brasileiro manifestaram-se contra a escolha dele como expoente da arte brasileira. A acusação de que Portinari era favorecido pelo Ministério da Educação era tema de polêmicas desde pelo menos 1935 e causou muito desconforto para o Ministro Capanema, que tentou até mesmo vetar, sem sucesso, a indicação do Pintor para a missão cultural nos Estados Unidos. Além disso, era boato corrente no círculo Capanema que as figuras deformadas, as mãos e os pés dos brasileiros pintados por Portinari, difundiriam uma imagem ruim do País. O impasse a bem dizer foi resolvido fora do País, pois Portinari era conhecido nos Estados Unidos e seu nome fora aprovado por Robert C. Smith, Alfred Barr Jr. e Florence Horn. Todos eles viam muita proximidade entre o realismo social norte-americano e a pintura de Portinari - o que caracterizava a tendência artística realista do Continente Americano em oposição à arte de vanguarda européia - com a diferença de que as obras de Portinari tratava $\mathrm{m}$ de mostrar a realidade brasileira, a nação ainda pouco desenvolvida e as camadas populares, o campesino e o trabalhador. Sem ter a intenção de fazer propaganda para o Estado Novo e sem conter uma mensagem política direta e revolucionária como os Muralistas Mexicanos, Portinari se adequava muito bem ao gosto do governo norte-americano. Ele tinha muita semelhança estética com as obras dos artistas da FAP, que em geral, promoviam o lema - o "trabalho reconstrói a nação" - e os feitos do governo Roosevelt.

No mês de junho de 1939, depois que se realizou a exposição "Arte Americana Hoje", ficou decidido que se deveria promover uma exposição de arte contemporânea latino-americana no Museu Riverside em Nova York, como atividade paralela à Feira Mundial de Nova York. Vários países latino-americanos e o Brasil enviaram obras para a exposição. Porém, a seção brasileira não contava com as obras de Portinari. Imediatamente,

3 Idem, ibidem, pp. 94-96. (colchetes nossos) 
quem tomou a palavra em defesa de Portinari não foi ninguém menos que Henry Agard Wallace, então secretário da agricultura do WPA, presidente da comissão da New York World's Fair e futuro vice-presidente dos Estados Unidos. Wallace disse: "(para os visitantes que foram ver a seleção de arte do hemisfério, a exibição trouxe uma grande decepção) (...) a decepção foi a seção brasileira, que parecia ter sido escolhida por um 'barman' míope, e consistia quase que exclusivamente em pálidas imitações do academismo europeu. Que uma arte nativa de vigor considerável estava se formando no Brasil, os visitantes da Feira Mundial já haviam percebido, através dos painéis do pavilhão brasileiro, pintados pelo popular e rechonchudo Cândido Portinari, do Rio de Janeiro. Não havia nada dele na mostra." 4

O "equívoco" das autoridades brasileiras seria corrigido na inauguração oficial do edifício do pavilhão brasileiro em 7 de setembro de 1939. Tota descreve: "Numa foto publicada no relatório elaborado pelo comissário-geral (Armando Vidal), (...) aparece Cândido Portinari (...). (E Tota comenta a passagem de Portinari pelos Estados Unidos:) Além da música, a pintura e a fotografia representavam uma outra face do Brasil nos museus americanos. Portinari, cujos quadros foram expostos no MOMA, mostrou um Brasil que muitos americanos não conheciam. Um suplemento em rotogravura de $O$ Estado de S. Paulo registrou, numa reportagem fotográfica a inauguração da exposição de Portinari em Nova York. O próprio pintor compareceu ao vernissage, realizado em fins de 1940. Antes, John Jay Whitney, o importante colaborador de Rockefeller, ofereceu um jantar no grã-fino restaurante 21, ao qual compareceram Portinari, Armando Vidal - que estava encerrando as atividades do pavilhão brasileiro na feira de Nova York - e personalidades americanas. Portinari, prestigiado na terra do Tio Sam, voltou aos Estados Unidos em meados de 1941. Três de seus murais podem ser vistos numa seção da Biblioteca do Congresso, confusamente chamada Hispanic Division." 5

Simultaneamente aos esforços do governo em promover o ingresso dos Estados Unidos no rol dos centros difusores de cultura para a América Latina, que culminaram com a Feira Mundial de Nova York, ocorria a

${ }^{4}$ Cândido Portinari. Catálogo raisonné. Projeto Portinari; diretor, João Candido Portinari. Rio de Janeiro: Projeto Portinari, 2003, Volume 5, p. 228. Cf. Também WALLACE, H. A. "Art of the Americas" In Time, New York, 12 de junho de 1939, pp. 36-37.

5 TOTA, A. P. Op. cit., pp. 97 e 106-107. (parênteses nossos). 
adesão de grande parte da intelectualidade e da comunidade de artistas norte-americanos à política oficial da administração Roosevelt. Se os Estados Unidos estavam preocupados em exercer influência duradoura no Continente Americano só poderiam conquistá-la através da criação de bases culturais sólidas, que tornassem o american way of life padrão a ser seguido pela maioria dos países latino-americanos. Com o tempo - logo após o final do conflito mundial - essa política ganhou força geográfica generalizadora e se estabeleceu internacionalmente. $O$ sucesso inicial da empresa governamental no âmbito das trocas culturais com os demais países das Américas e a tomada de posição política de intelectuais e de artistas se deram no momento em que Paris foi invadida pelas tropas alemãs no dia 14 de junho de 1940.

Para muitos intelectuais norte-americanos, entre eles, Archibald MacLeish, apenas os Estados Unidos com seus valores de liberdade e de democracia poderiam defender a civilização ocidental contra a barbárie nazista, por isso era necessário apoiar a nova política norte-americana para o mundo. Serge Guilbaut expõe qual era a questão candente para os intelectuais norteamericanos durante a queda da França: engajar-se na luta contra o fascismo ou não? E, mais ainda, de que modo seria possível isso? MacLeish era o porta-voz daqueles que condenavam a conivência com a política de neutralidade defendida pelo governo norteamericano sob pressão dos Republicanos.

Diz Guilbaut: "Em 18 de maio de 1940, a edição do Nation trouxe um artigo intitulado "Os Irresponsáveis" de Archibald MacLeish. MacLeish não era revolucionário, embora o partido comunista americano o tivesse cortejado durante a Depressão depois da publicação de sua carta aberta "Aos homens jovens de Wall Street". Ela continha um ataque contra a corrupção e a desigualdade e urgia que esses males fossem eliminados a fim de salvar o capitalismo, na opinião de MacLeish, o único sistema que permitia ao artista suficiente liberdade para desenvolver inteiramente seu talento. (Em seu artigo, Macleish fez um ataque virulento ao) (...) silêncio dos intelectuais americanos em face da guerra na Europa provocou uma longa série de polêmicas nas quais o Nation, a New Republic, e a Partisan Review tentaram definir o papel do artista e do intelectual em tempo de guerra."6

6 GUILBAUT, S. How New York stole the idea of the modern art - abstract expressionism, freedom, and the cold war. Chicago: The University of Chicago Press, 1985, p. 52. (parênteses nossos) 
Como Librarian da Biblioteca do Congresso, nomeado por Roosevelt, e em consonância com a Política da Boa Vizinhança, MacLeish convidou Cândido Portinari para pintar os murais da Fundação Hispânica. Embora tivesse se interessado pela arte de vanguarda européia, sua posição em 1940 seguiu mais de perto a de Hoger Cahill: MacLeish defendia o Realismo Democrático, e por semelhança Portinari, como expressão inovadora e legítima da arte nas Américas. Na política, MacLeish propunha que se formasse uma nova "frente popular" nos Estados Unidos, sem conotação política, para apoiar a entrada da nação norte-americana na guerra e para integrar os esforços de guerra contra o nazismo. Um valetudo em nome tanto da salvação da cultura contra a barbárie como do apoio à política internacionalista norte-americana.

Segundo Guilbaut, Dwight Macdonald compreendeu muito bem o que a proposta de MacLeish encobria, isto é: a defesa de uma arte nacional norte-americana: "Por baixo da bandeira da defesa nacional, estas teses (a de MacLeish e a de Brooks) atacavam o modernismo internacional e defendiam uma arte nacionalista agressiva. (MacLeish e Brooks) atacavam o nacionalismo nazista em nome do nacionalismo americano. De acordo com Macdonald e os remanescentes leais da esquerda independente tais como Farrell, a solução proposta era tão perigosa quanto o que ela atacava. Ambas as versões de nacionalismo apelavam ao artista para que desistisse inteiramente de seu papel crítico e se tornasse uma peça na maquinaria da política." 7

\section{A crítica de Mário Pedrosa: murais de Portinari em Washington}

Mário Pedrosa permaneceu em Nova York até sua expulsão do Secretariado Executivo da IV Internacional em 1940. No ano seguinte, ele tentou retornar ao Brasil, depois de ter viajado por cinco países da América do Sul: Peru, Bolívia, Chile, Argentina e Uruguai. Nesses países travou contato com militantes trotskistas a fim de organizar um novo movimento de esquerda ligado à ala dissidente da IV Internacional e próximo das posições dos intelectuais e dos líderes do recém-criado Workers Party (WP). Pedrosa entrou no Brasil pela fronteira do sul e, logo que chegou ao Rio de Janeiro, foi reconhecido e preso. Por intermédio de seu pai, conseguiu sair da cadeia e foi obrigado a viajar imediatamente para os

\footnotetext{
7 Idem, ibidem, p. 54. (parênteses nossos)
} 
Estados Unidos, onde passou a residir em Washington. Ali, ele fez contato com Leo S. Rowe, diretor geral da organização internacional União Panamericana. Por sua vez, Rowe contratou-o para trabalhar como colaborador do Boletim da União Pan-americana, em sua versão dedicada à cultura e às artes e publicada em língua portuguesa. ${ }^{8}$

No Boletim da União Panamericana são conhecidos três ensaios seus: um sobre o pintor Cândido Portinari, publicado em fevereiro de 1942; outro sobre a coleção Widener da Galeria Nacional de Artes dos Estados Unidos e outro ainda sobre o compositor Camargo Guarnieri, ambos publicados em 1943. A partir daí, Pedrosa pôde voltar sua atenção para as artes plásticas, oito anos depois de seu ensaio "Impressões de Portinari" de 1934. O novo ensaio sobre o pintor brasileiro foi intitulado "Portinari - de Brodósqui aos murais de Washington". Ele foi um ajuste de contas com os posicionamentos anteriores de Pedrosa e suas predileções pelo muralismo e pela arte filiada à revolução comunista. Na retomada de sua atividade como crítico de arte, Pedrosa encontraria nova chave interpretativa para a produção artística moderna dos anos subseqüentes. A execução dos murais de Portinari na Biblioteca do Congresso oferecia oportunidade de que Pedrosa não somente atualizasse sua compreensão da arte com base nas experiências por ele vividas e nas transformações ocorridas no cenário internacional, mas também propusesse uma nova tendência para a arte brasileira.

No ensaio "Portinari - de Brodósqui aos murais de Washington" de 1942, Mário Pedrosa apresentou uma alternativa possível para a continuidade e o desdobramento do trabalho plástico de Portinari. Um desdobramento inscrito na variedade de pesquisas plásticas realizadas pelo próprio artista. Tratava-se de apontar uma alternativa para o processo recente de instrumentalização das artes, evidenciado no realismo socialista, na arte raciada nazista e no realismo democrático dos Estados Unidos. Pedrosa estava ciente das circunstâncias que levaram o pintor brasileiro a ser escolhido como representante da "Arte Americana". Ainda que houvesse no continente americano uma tendência predominante do realismo, essa se tornava cada vez mais uma imposição para a construção necessária da identidade entre os Estados Unidos e os demais países do continente. Para os intelectuais norte-americanos que mantinham relações estreitas com o governo Roosevelt, as diversas exposições e as pinturas

\footnotetext{
8 Cf. PEDROSA, M. Política das artes. (org. Otília Arantes). São Paulo: EDUSP, 1995, pp. 353-354.
} 
murais de Portinari na Fundação Hispânica funcionavam não só como estreitamento dos laços dos Estados Unidos com o Brasil, mas também como forma de reafirmação e independência dos valores americanos frente à cultura européia.

Ao lembrar das palavras de MacLeish logo depois da inauguração dos murais em 12 de janeiro de 1942, Robert C. Smith comentaria o significado das pinturas de Portinari: "MacLeish declarou em uma carta para sua Excelência, o presidente Getúlio Vargas do Brasil, cujo interesse pessoal foi largamente responsável por tornar possível a viagem de Portinari a Washington, que a Biblioteca 'possuía não apenas pinturas bonitas que ilustravam o campo de interesses da Fundação Hispânica mas também uma altamente original e importante contribuição para a Arte Americana."”9

De modo geral, os escritos de Smith, de MacLeish e de Rockwell Kent enfatizaram o ideal da América unida em torno de ideais de democracia e de respeito mútuo entre os países. Foi nesse mesmo sentido que se afirmou muitas vezes que Portinari pintava as raças colonizadoras do continente (o negro, o índio, o branco) como forma de evidenciar o fato estratégico de que, na América, elas viviam em harmonia e construíam uma nova civilização. A Fortaleza Americana era construída para defesa dos interesses norteamericanos no continente, e os discursos sobre a democracia norte-americana e seu esforço em estabelecer laços mais duradouros com os demais países americanos encobriam os interesses estratégicos e a atuação política e econômica dos Estados Unidos no continente.

Como se sabe, o ensaio de Pedrosa foi criticado por Rowe, mas saiu publicado no Boletim da União Panamericana em 1942. Ele divide-se em três partes: a primeira trata dos problemas técnicos e estéticos que acompanharam Portinari em toda sua trajetória; a segunda evidencia o momento em que o pintor brasileiro se interessa pela matéria social e se encaminha para expressões plásticas mais coletivas; na última parte, Mário Pedrosa seleciona alguns exemplos e discute como Portinari conseguiu solucionar de forma mais completa a relação entre os problemas técnicos e estéticos em suas obras e alcançou uma expressão menos literária na descrição da realidade. Esse ensaio foi o ponto de transição entre a

9 SMITH, R. C. Murals by Cândido Portinari. Washington: The Hispanic Foundation of the Library of Congress, 1943, p. 09. 
avaliação de Pedrosa sobre o potencial revolucionário do muralismo e a defesa de uma arte livre. Era preciso fazer um ajuste de suas posições anteriores e lançar um novo caminho a ser trilhado pelas artes. Os murais de Portinari forneciam a ocasião. Visto que o realismo perdera sua função crítica, Pedrosa apontaria o distanciamento propositado das artes tanto do campo das ideologias quanto da produção para as massas como alternativa para que se preservasse o aspecto crítico, a natureza política e a ligação das artes com a revolução social.

Anos depois, Mário Pedrosa comentaria - em tom autobiográfico - o início de seu interesse pelas expressões mais livres na arte em confronto com a análise das fases de Portinari: "Ele era um artista social por excelência. Com isso queremos dizer que sua inspiração vinha de fora, do convívio cultural, das influências determinantes no momento, dos problemas da época. Sua vocação era "política", não no sentido estrito da palavra, pois nunca foi um político, mesmo quando se candidatou e foi eleito no duro senador pelo PCB, mas num sentido amplo, de gosto, de convivência, de comércio social, de participação. Magnificamente armado artesanalmente, ouvia e gostava de captar idéias e sugestões dos meios intelectuais que apreciava. Aqui, permitam-me, num parêntese, uma nota pessoal: em Washington, durante a guerra, quando Cândido Portinari chegou para pintar os painéis da Biblioteca do Congresso, retomamos a velha camaradagem e o velho papo de outros tempos. Um dia, ele havia acabado o painel dedicado ao ouro do garimpo. Era o painel mais audacioso e expressivo do conjunto e este um dos mais felizes na obra portinaresca." 10

Em seguida, Pedrosa discorre sobre sua impressão de que Portinari parecia seguir uma via mais livre e afastada dos excessos da literalidade na pintura. Essa impressão era condizente com os últimos trabalhos apresentados pelo pintor brasileiro em sua curta trajetória nos Estados Unidos, de Nova York a Washington. Contudo, o tempo não veio comprovar essa tendência. Por certo, Portinari interessava-se por retratar em suas obras pessoas simples, temas ligados ao trabalho e à exploração de camponeses e trabalhadores. Entretanto suas obras não tinham um tom político explícito, como se pode ver em alguns murais mexicanos. Diz Pedrosa: "Comentava eu, entusiasticamente, a maneira atrevida com que o

${ }^{10}$ PEDrosA, M. “A primeira Bienal” In Mundo, homem, arte em crise. São Paulo: Editora Perspectiva, 1986, pp. 261-262. 
pintor reduzia os detalhes figurativos, pé, nariz, cabeça, camisa, peneira, batel, água, pedra, etc., a manchas coloridas, a signos, a formas geométricas como triângulos, por exemplo, para realçar a força plástica significativa do todo, quando ele, com aquele seu jeitão esperto, à caipira, o bonachão, interrompe: ' - Pois é, eu aqui me sinto mais livre do que no Brasil. Os literatos me atrapalham'. Ele queria dizer com isso que as idéias forçosamente literárias dos intelectuais amigos interferiam freqüentemente com as suas, ou os seus projetos puramente pictóricos. E ele nunca soube, com efeito, se livrar delas. No princípio de sua carreira, eu também, então seu amigo e freqüentador, me incluo entre aqueles intelectuais."11

\footnotetext{
${ }^{11}$ Idem, ibidem, p. 262.
} 